\title{
Successful removal of a bezoar: treatment of a rare complication after Billroth II surgery
}

A 68-year-old man presented to our hospital with paroxysmal abdominal pain for 2 months. He had undergone a Billroth II operation 11 months previously, and esophagogastroduodenoscopy at another hospital 1 month ago had shown an anastomotic ulcer. However, his abdominal pain had not been relieved by administration of strong proton-pump inhibitors.

Therefore a computed tomography (CT) scan was performed, which revealed a foreign body in the efferent loop and uneven thickening of the gastric wall ( Fig. 1). Esophagogastroduodenoscopy at our hospital showed residual sutures, accompanied by ulcers, at the beginning of the efferent loop and anastomosis ( $\triangleright$ Fig.2). To identify the foreign body, the endoscope was deeply inserted into the efferent loop and the afferent loop. We found that the longest sutures were about $10 \mathrm{~cm}$ in length, and that their distal ends formed a ring that entangled a bezoar of size $2 \mathrm{~cm} \times 3 \mathrm{~cm} \times$ $8 \mathrm{~cm}$, hanging deep in the efferent loop ( Fig.3, Fig.4). However, the afferent loop was clear. We suspected that the sutures, which had become free from the anastomosis, had entangled undigested food thus leading to the abdominal pain ( $\mathbf{F i g . 5}$ ).

Therefore, stitch scissors were used to cut down the residual sutures. Then we trapped the bezoar and dragged it out using a snare ( $\triangleright$ Video 1 ). The procedure took 40 minutes. The patient's abdominal pain was relieved promptly and he received medical therapy with aluminum sulfate prokinetics and lansoprazole. Reexamination 1 month later showed both the afferent loop and efferent loop were clear without any discomfort. Of note, we took biopsies during every esophagogastroduodenoscopy and they all revealed chronic inflammation.
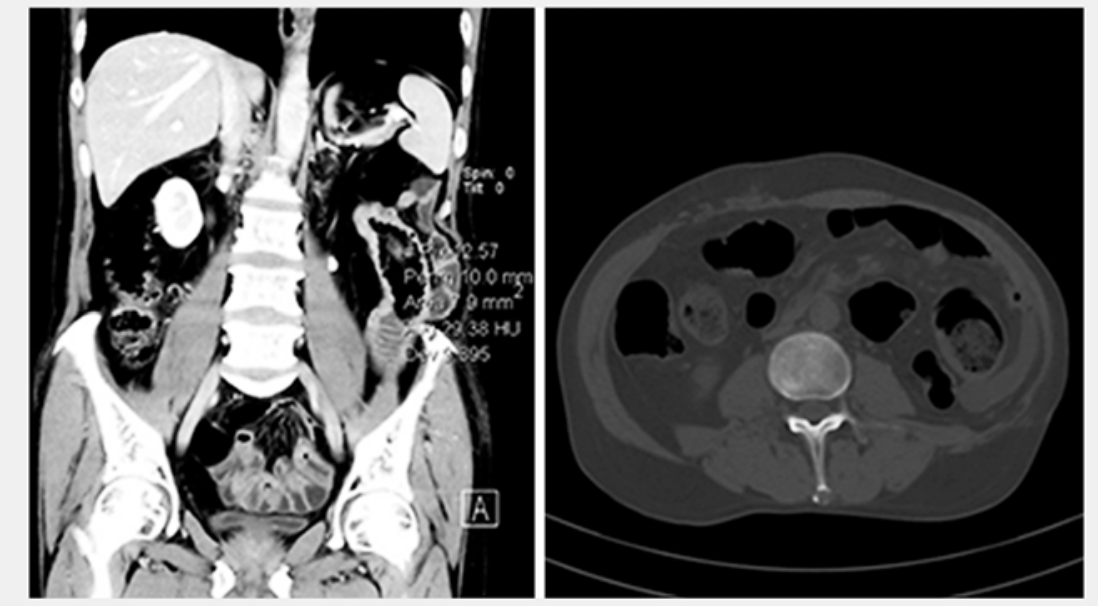

- Fig. 1 Computed tomography (CT) scan shows a foreign body in the efferent loop and uneven thickening of the gastric wall, in a patient who had undergone Billroth II surgery 11 months previously.

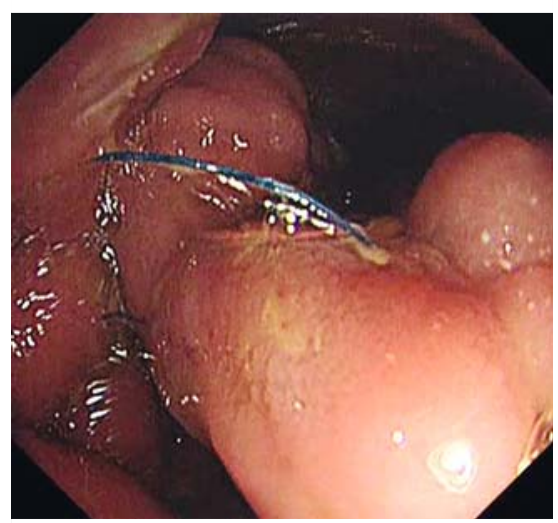

- Fig. 2 Endoscopic examination shows residual sutures at the efferent loop and the anastomosis.

Efferent loop syndrome refers to purely mechanical complications in efferent loops following gastrojejunostomy, and bezoars are rare causes of efferent loop syndrome [1]. This is the first case of abdominal pain induced by a bezoar caused

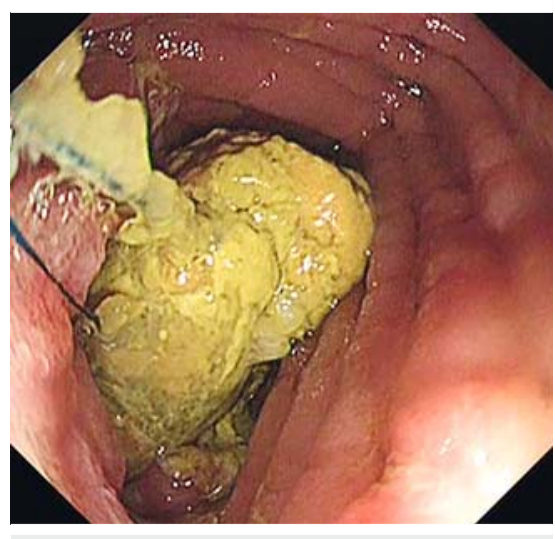

Fig. 3 A giant bezoar entangled with sutures within the efferent loop.

by residual sutures, to the best of our knowledge, and we successfully removed the bezoar by endoscopic intervention.

Endoscopy_UCTN_Code_CCL_1AC_2AH 


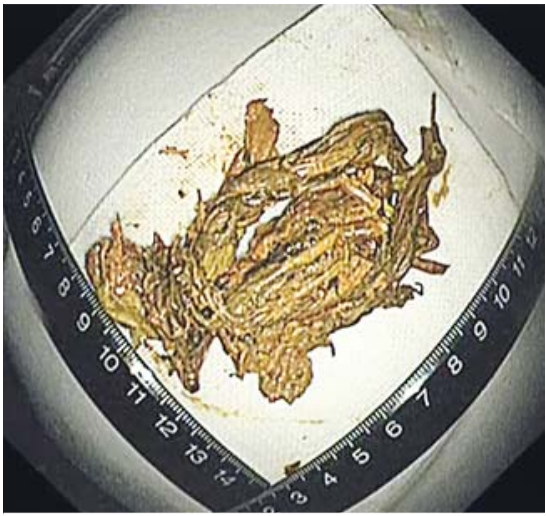

Fig. 4 Bezoar of size $2 \mathrm{~cm} \times 3 \mathrm{~cm} \times 8 \mathrm{~cm}$.

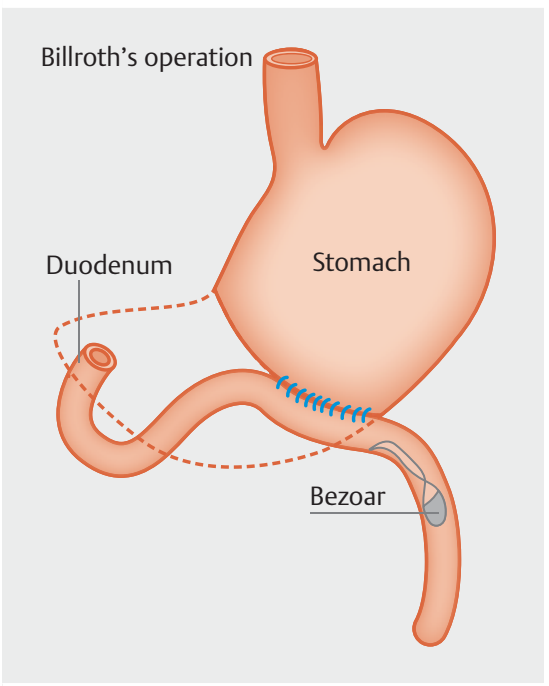

- Fig. 5 The residual sutures may have caught undigested food, leading to the obstruction.

\section{Competing interests}

None

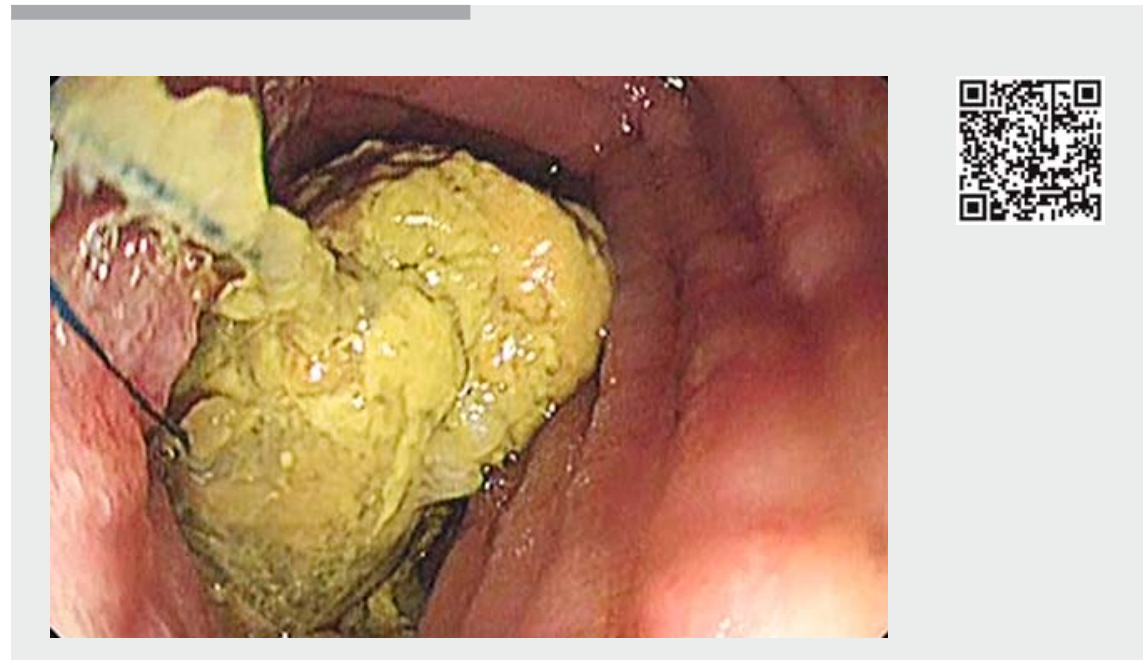

Video 1 Endoscopic removal of a bezoar from the afferent loop in a patient with Billroth II anatomy.

The authors

\section{Yajun Shou, Yuyong Tan, Deliang Liu}

Department of Gastroenterology, Second

Xiangya Hospital of Central South University,

Changsha, Hunan, China

\section{Corresponding author}

\section{Deliang Liu, MD}

Department of Gastroenterology, Second Xiangya Hospital of Central South University, No. 139 Middle Renmin Road, Changsha, Hunan, 410011, China Fax: 86-731-85533525 deliangliu@csu.edu.cn

\section{Reference}

[1] Lee WY, Moon JS. Endoscopic treatment of efferent loop syndrome with insertion of double pigtail stent. World J Gastroenterol 2013: 19: 7209-7212

\section{Bibliography}

DOI https://doi.org/10.1055/a-0593-5679

Published online: 9.5.2018

Endoscopy 2018; 50: E157-E158

(c) Georg Thieme Verlag KG

Stuttgart $\cdot$ New York

ISSN 0013-726X

\section{ENDOSCOPY E-VIDEOS}

https://eref.thieme.de/e-videos

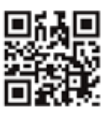

Endoscopy E-Videos is a free access online section, reporting on interesting cases and new

techniques in gastroenterological endoscopy. All papers include a high quality video and all contributions are freely accessible online.

This section has its own submission website at

https://mc.manuscriptcentral.com/e-videos 